\title{
Et Tu Ru? Entrepreneurship and the Commodification of Drag in RuPaul's Drag Race
}

\author{
Jonathan Buck
}

\begin{abstract}
:
Historically, drag is a taboo which has been marginalized in the face of centuries of repression against non-heteronormative activity. Yet today drag has become highly visible in popular culture, and this is in large part attributable to the international success of American reality TV show RuPaul's Drag Race (2009-present). Its bold representation of drag on a mainstream television show is unprecedented and the selection of drag queen competitors by the show's producers has demonstrated a plethora of representations as Drag Race showcases a diverse range of identifications from the world of drag performance. The blossoming of Drag Race's success comes at a historical moment in which we are seeing a huge proliferation of queer representations (re)produced in US television and other media over the last decade. However, as I will argue, the apparent liberalization of drag queens in popular culture is not simply a celebration of so-called 'progress' in the recognition of the marginalized, but may also be prompting the promotion of other value changes within late capitalism's ideals of consumerism and entrepreneurship. Contestants are increasingly pressured to construct their drag performances to conform to a recognizable brand to reach the heights of their own private 'success'. Mainstreamed depictions of queer subjects are susceptible to co-option, particularly in televisual forms such as Drag Race which prospers by channelling the emancipatory and subversive desires of the subculture. Through trans-textual considerations and historical contextualizations, I show how the representation of drag in Drag Race is depoliticized through neoliberal discourse as the show's continual demand for competitors to 'work it' privileges and maintains the impetus for competitive profitmaking above the needs and demands of disempowered groups.
\end{abstract}

Keywords: drag, rupaul, queens, gender, neoliberalism, entrepreneurism

\section{Introduction}

Drag is a performance art which has a long and varied history in commercial and underground clubs, bars and ballroom culture. Drag has appeared in both queer and heteronormative audience contexts and it has (with some exceptions) been marginalized, often even within queer culture (see Strübel-Scheiner 2011: 12). Yet today, drag has become ever more visible in pop culture, and that this is in large part attributable to the international success of US reality TV show RuPaul's Drag Race (2009-present) cannot be understated. The hyper-visibility of drag on a mainstream show is unprecedented and its 
selection of drag competitors brings to view a plethora of identifications. From showgirls and fishy queens ${ }^{1}$ to trans and HIV+ contestants, Drag Race showcases a diverse display of drag performers. The blossoming of Drag Race's success comes at a historical moment in which we are seeing a huge proliferation of queer representations (re)produced in US television and other media over the last decade. However, the apparent liberalization and engagement with drag queens on the show and its inchoate celebration of 'progress' in the recognition of marginalized social groups is dubious. Careful attention should be given to how Drag Race prompts value changes within neoliberalism's ideals of consumerism and entrepreneurship. Neoliberalism has increasingly been understood as constructing individual subjects into entrepreneurial actors who are autonomous and self-calculating, and who must bear the responsibility for their lives no matter the constraints of poverty, racism, sexism, and so on. Drag Race reaffirms this ideology by emphasizing the supposed liberatory qualities of entrepreneurism through its competitive format. Mainstreamed depictions of queer subjects are thus particularly susceptible to co-option, especially in televisual forms such as Drag Race which thrives by channelling the emancipatory and subversive desires of a subculture. As I will argue through an intersectional analysis, the show's continual demand for competitors to 'work it' privileges the impetus for competitive profit-making above the tangible needs and demands of disempowered LGBTQ communities.

I will explore how the multiple identities on display with particular attention to gender, race, and class, and how the institutional stricture of the show constrains and suppresses particular identifications. I will look at the ways its representation of drag is necessarily inhibited by its televisual form which is reliant upon sponsorship, advertising, and viewing figures. As part of my research, I have watched through all the seasons of Drag Race to date as well reading relevant scholarly literature with particular attention paid to the work of Judith Butler and her Foucauldian position around 'normative' discourse.

1 In the world of drag, 'fishy' is an adjective used for queens who strive for a look which is very feminine or which most resembles a cisgender woman. The term refers to the smell of vagina which is colloquially likened to the scent of fish. 


\section{Freaky Money}

In each episode of the show, Drag Race contestants are expected to compete in a set of challenges. Each episode follows a uniform format consisting of a mini-challenge, the main challenge, a runway (where the contestants model their own dresses on the runway, usually upon a theme drawn from the main challenge), a judges' critique, and finally a 'lipsync for your life' followed by the elimination of a contestant. Challenges have previously involved acting, stand-up comedy, dragging a straight partner, applying make-up in half an hour, or 'reading' their opponents (in which the queens give playful taunts to determine who is the 'shadiest' of them all.) During the challenges, it is stressed by the show that to win it is important that each queen should appear relatable to mainstream audiences while simultaneously evoking something creative or personal about themselves. During the challenges, each contestant is expected to project a fierce competitive spirit. While 'fierce' in the drag world is a term that denotes the attitude needed to face the hostile discrimination faced in daily life, in the terms of Drag Race 'fierce' is understood as the entrepreneurial spirit which marks out winners from their competition. RuPaul herself has become the exemplar of this with the Oprah-esque philosophy of self-help she extolls to the contestants (Kent 2013). The imposing figure of RuPaul comes to stand in as the apex of achievement which the competitors should strive to emulate. Her commercial appeal (and therefore her own commodification) is continually invoked as a shining example for the contestants. The criteria which RuPaul uses to judge the competitors by her own standard are what she calls the qualities of 'C.U.N.T': charisma, uniqueness, nerve and talent. These nebulous virtues mirror what Costa and Saraiva define as typical entrepreneurial characteristics. These include four discursive objects: 'a proactive search for knowledge', 'sharing experiences', 'new ways of doing things' and 'putting into practice' (Costa and Saraiva 2012: 596).

As Judith Butler has asserted, gender is formed through a performative effect, and she argues that it has no a priori state outside of a persistent practice which ceaselessly reproduces itself (Butler, 1990). She argues that drag foregrounds how all gender is both performative and iterative. Femininity is unravelled as a cultural regime; an act of doing not 
being. Drag performance thus reveals how bodies are coerced into gender acts or roles by culture. RuPaul has her own provocative assertion: 'We are all born naked, and the rest is drag' (RuPaul 1995: 15). With this in mind, Drag Race has undeniably been significant for television audiences as it engages viewers directly with how a gendered persona is cultivated. The show brings to the mainstream the actual lived experiences of drag queens to viewers who might have no exposure or access to these representations otherwise. Contestants often give in-depth oral accounts of their own experiences as drag queens, and these descriptions encapsulate the positives (the comradery and family-building attributed to the drag scene) and the negatives (the bigotry and violence they have encountered). Although these confessional moments are predictably heavily edited by the reality show format, one would be hard-pressed to think of another show that has allowed drag queens such a three-dimensionality; it is arguably the most 'drag-friendly' show in television history. But to properly analyse Drag Race one must read the contested relationship between the world of drag and the reality TV form, and how this relationship might reproduce normative discourse. As John Fiske comments:

The preferred meanings in TV are generally those that serve the interests of the dominant classes: other meanings are structured in relations of dominancesubordination to these preferred ones as the social groups that activate them are structured in a power relationship within the social system. The textual attempt to curtail meaning is the semiotic equivalent of the exercise of social power over the diversity of subordinate social groups. (Fiske 1990: 126-127)

The move from drag in bars and clubs to the small screen shifts the meaning of the drag queen's gestures until they are commensurable to the dominant discourse of mainstream television. The show is necessarily always looking to maintain sustainability and find further profit as it seeks out a market beyond the 'pink' economy of Logo TV (a channel primarily aimed at an LGBTQ audience). In the world of Drag Race, American life is postulated as being past oppression, and what remains is for individuals to prove their selfworth. Through the iconic resonance she carries in the LGBTQ community, RuPaul is instrumental in dishing this discipline out. RuPaul is positioned as the ultimate authority figure of the show, as although the competition has a judges' panel, it is RuPaul that 
always has the final say à la The Apprentice (2004-2017). As the show continues to broaden its audience ${ }^{2}$ it aims to expand its viewership and marketability by drawing the various 'exotic' identifications of the drag queens into a more palatable and consumable frame, well-represented by RuPaul who personifies a sanitized form of drag which reproduces an aesthetic of whiteness rather than challenging it. 'Otherness' is sublimated into hollow tokenistic gestures which the show repeats ad nauseam, so that race, gender, and sexuality become presented as a lifestyle choice, while a centrally white gender binary is reified. As Butler notes, '...here it seems wise to re-invoke Foucault who, in claiming that sexuality and power are coextensive, implicitly refutes the postulation of a subversive or emancipatory sexuality which could be free of the law' (Butler 1990: 40). Failure for the contestants to assimilate to the constraints encouraged by the show results in harsh criticism to shape their drag until it is a 'success' (i.e. profitable), or in some cases outright rejection.

\section{Supermodel (You Better Work)}

It is crucial to understand how the commercial concerns of a show like Drag Race motivate the content therein. Drag Race reaffirms (and thus reifies) a narrow and non-threatening form of drag which it uses to sell its products to a mainstream audience. The show's production is reliant on product placement to function, and Kai Kohlsdorf (2014) contends that this determines the normative expectations of the show through a pervasive attitude of 'sameness' which represses the potential for gender subversion as well as perpetuating an apolitical atmosphere which revels in neoliberal post-race and postfeminist ${ }^{3}$ discourse (Kohlsdorf 2014: 67-87). Although the show routinely pays lip service to the historical sites of civil rights struggles (such as the invocation of the Stonewall riots), this is sublimated

\section{In 2017 the show moved to VH1 and is currently streaming on Netflix.}

3'Postfeminism' is a contentious term which emerged in the late $20^{\text {th }}$ century within varying cultural, academic, and political contexts. Unlike pre-feminist constructions of gender, postfeminism is unique in that it is a reaction to feminism, contradictorily hailing the empowerment of women in various social spheres whilst simultaneously re-inscribing the female body as a sex object. As Rosalind Gill has argued: 'It is precisely in the apparent contradictoriness of the postfeminist sensibility that the entanglement of feminist and antifeminist discourses can be seen' (Gill 2007: 62). My own understanding of postfeminism is as a form of neoliberal rhetoric which is used to neutralize feminist concerns and criticism. 
into a viciously competitive individualistic ideology. Likewise, where the show highlights shared experiences of discrimination, HIVIAIDS, and body dysmorphia, this is undermined by presenting drag within a competitive TV context dependent on product placement (Daems 2014: 6). The show exploits its competitors to advance marketing and advertising for the products of its commercial sponsors, irrevocably commodifying (and thereby altering) their performances. While many contestants already have high profiles within the drag scene prior to appearing on the show, entering the competition alone boosts their career, and with a large cash prize at stake, many queens are all too happy to adjust their act to the show's demands. Several contestants have since gone on to lead successful careers as recording artists, actors, and as stand-up comedians. RuPaul herself has been quite upfront about what is expected from competitors: 'What we're looking for is someone who can really follow in my footsteps: Someone who can be hired by a company to represent their product, someone who can put together a sentence on television and present themselves in the most incredible way' (Buchanan 2011). Although each queen is encouraged to express herself in the competition, this expression is always within the confines of what RuPaul expects and what the show's producers want to extract in value from its contestants; drag as a homogenous product.

In Drag Race, drag performance is celebrated through the lens of the highly individualistic ideology of entrepreneurship. With the neoliberal turn, the doctrine of entrepreneurship is reflective of how all manner of human activity has been increasingly brought into the realm of the market (Harvey 2007: 3). Neoliberal ideologues have long embraced entrepreneurship as both a means into an ever more fiercely competitive labour market as well as providing what Broderick Chow calls a 'panacea to neoliberalism's collateral damages' (Chow 2017). In each episode of the show, one can see how ideals of the LGBT community (such as collective struggle and solidarity) are displaced by an emphasis on individual freedom and personal wealth (Cohen and Musson 2000: 31). Paradoxically, neoliberalism also suggests that anyone can potentially become an entrepreneur and thrive within a free market economy so that the notion of achieving individual wealth appears less rarefied (Kruger and Brazael, 1994). As we see workers worldwide following the 2007-2008 financial crisis being told they are now free to work for themselves, so too in Drag Race we see how the art of drag performers becomes drawn into a work-driven 
ethos. In Drag Race entrepreneurship becomes expressed through drag as a neverending body, fashion, and makeup project. The show goes to lengths through its editing to give a condensed impression of the hours of hard work that drag performers go through in the construction of a gender persona. Independence, creativity, and liberty become manifested in everything from their dress, makeup, countenance, and carefully groomed hairlessness, and in the physical and mental challenges they face in the show. While viewers may find a new-found admiration in the labour that goes into drag, this privileging of work also narrows an understanding of drag into dog-eat-dog notions of perpetual competition and underplays how drag scenes have often historically functioned as a collective and inclusive space for minority groups.

Central to the figure of the entrepreneur is the notion that the free market cultivates society into a classless meritocracy where a fruitful career can be attained by anyone who truly strives to achieve it. While Drag Race frequently alludes to the poorer backgrounds of many of its contestants during RuPaul's one-to-one backstage critiques (as well as her own humble beginnings), RuPaul always stresses that being poor should not be a block to success. In Season 8, contestant Chi Chi DeVayne told RuPaul about her struggle to put together an impressive dress on the runway. Back at her home in Louisiana she worked a minimum wage job, had since become bankrupted by debt, and simply did not have the funds to afford decent material to put a good dress together (unlike many of the other queens who brought in designer items with them to compete). This was immediately seized upon by RuPaul as a weakness in her work ethic, and she was advised that a real drag queen could always 'make it work' with whatever material was readily available. The phrase 'when life gives you lemons make lemonade', is often repeated on the show, and any queen that dares to bring up material disadvantage inevitably faces criticism by the judges or the other contestants.

Contestants from rural southern or mid-west backgrounds are coached into toning down or losing their accents altogether so that they can perform what RuPaul calls 'TV-speak' correctly. Likewise, contestants of Latino or South-East Asian heritage such as Manila Luzon and Kim Chi were pressured into negotiating their accent (and by extension their racial identifications) by either downplaying it or by presenting it as a broad stereotype. 
The erasure of class and ethnic identity and the upholding of what Libby Anthony calls 'Standard English ideology' (Anthony 2014: 51) speaks not just to the bias of RuPaul and her producers but to a cultural disavowal of class and immigrant identity that is necessary for the construction of the entrepreneur. Those from poor (and often BAME) backgrounds are expected to be able to 'work it' just as much as their more privileged competitors. Yet with a $\$ 100,000$ cash prize on offer, the stakes are significantly higher for some competitors than for others, particularly those who have not yet built a public profile and often leave a low-paying day job to risk competing on the show.

In season 10 of Drag Race, contestant Asia O'Hara found out the hard way what happens when a contestant transgresses from the entrepreneurial narrative embedded in the show. In one episode during the lead up to the weekly challenge she helped each of the other contestants to sew their dresses, drawing on her career experience as one of the older queens from the season's slate. In doing so she temporarily took on the role of the 'drag mother'. In the world of drag, the drag mother represents a more seasoned queen who takes on aspiring queens and gives these ingénues a useful mentor-apprentice relationship as well as emotional support. Butler argues that the truly subversive element of drag is not the mimicking of femininity, which '....actually reinvests the gender ideals; it re-idealizes them - reconsolidates their hegemonic status'. Rather it is these new kinship systems, which '...do mime older nuclear-family kinship arrangements but also displace them, and radically re-contextualize them in a way that constitutes a rethinking of kinship, or that turns kinship into an extended community- one whose future forms can't be fully predicted' (Butler 1992: 84, original emphasis). After the runway challenge, O'Hara's dress was criticised by the judges for not being up to her own high standards. She confessed that she had not been able to manage her time effectively in preparation for the challenge as she had spent much of it giving assistance to other queens in need. The other queens confirmed this and attested to her altruism. But while the judges admitted this was 'sweet', they were unequivocal in condemning her actions in what is supposed to be a cash prize competition. Although Drag Race adopts the language of empathy, in practice it discourages co-operation in favour of individual goals. 


\section{Gentlemen, start your engines and may the best woman win!}

Like many drag queens, RuPaul uses gender pronouns interchangeably. In her autobiography, she writes 'You can call me he. You can call me she. You can call me Regis and Kathy Lee! I don't care! Just as long as you call me' (RuPaul 1995: 140). Drag Race nevertheless narrows the gender expression of the queens, rendering some identifications invisible (thus naturalizing them) in order to make the queens as 'presentable' as possible (thus commodifying them). This is achieved through the editing of the show which largely defines the narrative the audience consumes and RuPaul who can evict any queen who does not conform to her expectations. The judges openly discourage any gender-bending that goes 'too far'. The runway challenge is exceptionally revealing in this regard. In Season 4 contestant Milan emerged in a Janelle Monae inspired look for the runway. She immediately faced brutal criticism from the judges, with Michelle Visage telling her 'You look like a drag king. I felt like I was seeing Sammy Davis Jr. That is not what I want to see in my drag queens.' Milan was summarily evicted in the following episode after she continued to challenge the judges' criteria (Brennan 2017: 36, original emphasis).

At the beginning of each episode, RuPaul starts the challenges by telling the contestants: 'Gentleman, start your engines and may the best woman win!'. The emphasis RuPaul places on 'woman' is deliberate, as it reifies the assertion that drag is only a 'play' upon the reality of womanhood to a mainstream audience (Kohlsdorf 2014: 71). Notably, when RuPaul appears backstage she is always out of drag (or in what she refers to as 'male drag') and each episode is split between showing the queens backstage out of drag preparing for the challenges in which they appear dressed and tucked as their personas. In presenting the backstage of the queens as the real and their performances as fantasy the show makes a sharp distinction between two worlds, and this acts to reduce the viewer's understanding of drag performance as being solely about gay cisgender men who can perform femininity well.

This is exemplified in a season 2 episode in which the weekly challenge involved the queens taking part in a wedding photo shoot in which each competitor appeared as both 
the bride and groom. While one could argue this is a playful queering of heteronormativity, in the context of a reality TV show hailing a mainstream audience it is difficult not to see this as a reification of gender norms. To 'pass' as a woman in Drag Race does not mean to fool the public that the queen is a cisgender woman but rather to pass as a performer of womanhood. The show continually emphasizes that drag is an essential transformation from a 'real' man into a fantasized female figure. Yet as Butler reiterates there is no 'real' to begin with. To believe so is to confuse performativity with performance. When the cameras turn off an actor stops playing their role. But a body cannot just reject gender as gender is dependent on the cultural norms of social structures and the witnesses therein which render performative gestures legitimate or not (Butler 1993). Non-binary or trans identification thus represents a threat to the straightforward 'either/or' binary gender structure of Drag Race, and as a result, these identifications are continually repressed.

\section{The Realness}

This notion of an essentialist transformation is also related to the category of television which Drag Race inhabits. As reality television, Drag Race follows a competitive format which emulates and parodies shows like American's Next Top Model (2003-present, hereafter to be referred to as ANTM) and Project Runway (2004-present). It also falls into the genre of the make-over show. Make-over shows have tended to focus on female subjects and their transformation (via make-up, fashion, or in the more extreme versions, plastic surgery) into a more beautiful version of themselves. Brenda Weber has argued that there is a corrective function of make-over shows which disciplines its participants to conform to the sociocultural norms of femininity (Weber 2008: 77-79). Those taking part in these shows are ritualistically shamed for their appearance by the show's host, their peers, or the public. Ironically, this hazing often uses the feminist language of empowerment to justify itself on the basis that the transformation will lead to a heightened sense of selfesteem and fulfilment for the subject(s). Foucault explains that where premodern culture relied on torture and public spectacle to discipline disobedient bodies, he believes the modern epoch is defined by what he calls 'panopticism'. Just like the prisoner subject to the gaze of a warden's panopticon, the contestants know that they are under constant 
scrutiny; from the television cameras, the judges, the other competitors, and, crucially, themselves. The individual contestant interiorizes this gaze and thus becomes a selfpolicing subject. 'There is no need for arms, physical violence, mental constraints. Just a gaze. An inspecting gaze which each individual under its weight will end up interiorizing to the point that he is his own overseer, each individual thus acting this surveillance over, and against himself' (Foucault 1977: 155). As Laurie Norris notes, 'One of ANTM's lingering influences on Drag Race is the way both shows manipulate their contestants and mould them into conforming to established notions of beauty' (Norris 2014: 34). ANTM propounds that a woman only becomes a 'real' woman through the correct consumption of products, and Drag Race applies the same logic with its own contestants as queens are policed by the judges (and each other) to show their 'realness'. Realness is a term derived from the drag ball scene and is used to define how well a queen's illusion passes as authentic (Marcel 2014: 15). In Drag Race to project this quality of realness they must make-over themselves into an ideal image of a woman and present this image as bona fide. In her exploration of the drag documentary Paris Is Burning (1990), Butler notes that to perform this realness produces a naturalizing effect which results from the impersonation of gender norms, for which she again stresses there is no archetype (Butler 1993: 129).

In the pursuit of 'realness,' many queens on Drag Race have admitted to the use of plastic surgery to look more 'fish' (authentically woman-like). The use of plastic surgery is not against the rules or discouraged by the show, despite the fact it hardly presents an even playing field, dividing the queens as it does between those who can afford cosmetic supplements and those who cannot. The approval of surgical transformation, however, is restricted to a strict gender binary logic. While Chad Michaels, a Cher-impersonator, can enthusiastically acknowledge the use of plastic surgery to achieve her look on the show, transitioning trans contestants have been discouraged by RuPaul from competing at all (Aitkenhead 2018). As a result, despite the reality that many queens in the world of drag identify as trans, the show continually resists these identifications so that the queens are as easily categorizable as possible and do not offer up unwanted challenges for viewers. It is clear in the history of the show that trans contestants have not felt comfortable being out in the Drag Race space. Several contestants, the first being Carmen Carrera from Season 3, have come out as trans but only after appearing on air. In an environment 
where gender meshing is discouraged and a backstage where the competitors must untuck to reveal their innate maleness to the cameras, this is hardly surprising. Former contestants like Carerra who have found success post-Drag Race have been publicly critical of the show in the press and online, particularly of the transphobic language and ideology utilized by RuPaul. The show in turn has adapted to this criticism, most notably in removing the pejorative 'she-male' from the segment of the show where RuPaul breaks down the first challenge for the contestants. Of course, it is difficult not to read this as a cynical reaction on the part of the show's producers to placate critics and to retain the LGBTQ audience which still constitutes much of its core viewership. Indeed, to this degree Drag Race is representative of the wider tensions within the LGBTQ audience as many gay and lesbian critics have argued that trans should no longer be included in their political banner (see Roberts 2016). RuPaul later felt compelled to defend her own use of the word 'tranny' (Molloy, Reynolds \& Brydum 2014), while season 6 winner Bianca Del Rio publicly gave a tirade of abuse aimed at Carerra in which she joked, 'Maybe she should take what's left of her dick and stick it in her mouth and shut the fuck up...let's face it, we wouldn't know who the fuck Carmen Carrera was if she didn't fucking get on Drag Race." This kind of vitriol was then followed by a slew of similarly abusive comments by Facebook users on Carrera's page. Drag Race is apparently beyond criticism, and any contestant who does so is accused of biting the hand that feeds her.

\section{The Shade Of It All}

These moments of controversy in the show's history have proven to be a constantly shifting negotiation between its producers and its audience. The narrow logic of the show has faced increasing critical scrutiny, particularly its racial bias and its transphobic tendencies (see John 2018). The players themselves have responded to these issues and have on occasion challenged the nature of the game and RuPaul's authority. In the penultimate reunion episode of the most recent season of Dragrace, contestant Vixen insisted that the show continued to demonstrate a favouritism of white queens. After a heated exchange with RuPaul, she walked off the show. In Season 5, Monica Beverly Hillz became the first contestant to openly identify as trans while the show aired (though 
the fact that she initially felt this needed to be hidden again speaks to the air of exclusion which permeates Drag Race.) Though the judges gave supportive comments following this reveal, and some of the contestants also voiced their solidarity (Jinkx Monsoon, the eventual winner of the season, described her during the episode as her 'hero') in the following episode Hillz was eliminated. In season 9 queen Peppermint became the first trans-identified contestant to appear on the show who was already out before airing (though again, she did not feel comfortable disclosing this to the other contestants until the season was well underway and she transitioned after it had finished). Although she survived the entire season to become first-runner up, in the end she was eliminated in favour of Sasha Valour; a white cisgender queen. In an interview following the season, RuPaul admitted that she would 'probably not' have allowed Peppermint to compete had she transitioned before the season began airing (Aitkenhead 2018).

Trans queens are not the only ones to be targeted for exclusion on Drag Race, however. Contestant Ongina became a cause célèbre with the LGBTQ press when she came out as HIV-positive on Drag Race's inaugural season. After an emotional revealing of her status in episode 4 of the season, Ongina instantly received positive words of acceptance from the other queens as well as the judges panel. Guest judge Espinet told her: "You know, at the end of the day, yes, it's a serious issue, but we have to always try and look at the brighter side of life, and I think you did a great job of it." Yet this message was quickly shelved when it came to the judges' critiques for the weekly challenge. This episode involved being a spokesmodel for Viva Glam; a brand set up by the make-up company M.A.C. which is currently the largest non-pharmaceutical donator to HIVIAIDS causes. The empowerment of Ongina and her potential value to educate others about HIV was set aside as the judges instead discussed her capacity to 'represent' Viva Glam, which for the judges meant her capability to sell makeup to new markets using the corporate language of philanthropy. In Drag Race the highlighting of HIV issues harnessed through years of campaigning in the LGBTQ community is mediated through the pushing of make-up products. Indeed, Hunter Hargraves (2011) argues that 'Drag Race can be read as hollowing out HIV, erasing its claims to bodily violence and instead repackaging the epidemic as corporate goodwill' (Hargraves 2011: 29). Typical to Drag Race form Ongina was swiftly evicted in the following episode. Ongina has since gone on to become an HIV 
activist with her own Logo series HIV + Me (2014-present), yet despite her popularity outside Drag Race she has yet to be invited back onto the spin-off show RuPaul's Drag Race: All Stars (2012-present).

Contestants are expected in the 'out of drag' segments of the show to reveal something of their core personality and their lived experiences as drag performers. Direct discussion amongst the queens has previously involved gay rights issues, homophobia, sexual assault, and HIV. Often, contestants seem compelled to emote on these issues as much as possible to gain emotional currency and to later curry favour with the judges panel. As Marx notes in his analogy between the wage labourer and the sex worker: "You must make everything that is yours saleable, i.e. useful' (Marx 1844). In Drag Race this includes emotional as well as physical labour, though these emotional outbursts also have their own limits set by the show. While there is undeniably a positive element in presenting minorities articulating these issues themselves to an audience which may not have easy access to these topics, it is crucial to understand how these discussions are skewed through the lens of the reality TV format and confined and controlled by dominant discourse. In other words, discourse is not a closed circuit which is produced, reproduced, resisted, and changed. It is the active relation between discourse and society which ensures that the production of discourse is controlled and maintained through procedures which ensure its powers and dangers remain within the dominant hegemony. As Foucault (2007: 9) notes, 'One knows very well that one doesn't have the right to say everything, that one can't talk about everything in every circumstance, that anyone, after all, cannot talk about anything'. This was notably borne out in season 10 of Drag Race when competitor Blair St. Clair tearfully broke down during the judges' critique and spoke out about having been raped at college. Though the judges and fellow queens were sympathetic in their support of St. Clair, she was nevertheless evicted the same episode following the runway challenge. A survivor of rape was simply not assimilable to the homogenous drag queen product the show requires for the palate of its commercial sponsors.

\section{Conclusion}


I have explored the representations of drag in Drag Race and how consumption and competition ultimately come to define these representations through the narrative the show constructs. This mainstreaming necessarily limits the viewer to a simpler comprehension of drag as the show strives to contain contradictory representations and constrain gender performativity within its institutional boundaries. Drag Race forms a normative set of expectations, conditions, and categories to drag which in fact are not analogous to the history of drag performance. Many drag scenes (particularly in the ballroom) have an understanding of drag as a complicated and fluid exploration of gender, race, and sexual orientation. But the show's producers know full well that it is the kind of drag and gender presentation that RuPaul represents which sells products (Kohlsdorf 2014: 70). The performance of drag is denoted as talent, and talent is posited as what can lead contestants to the fame and wealth embodied by RuPaul. The connections the show makes to a wider LGBTQ history and community become increasingly spurious as civil rights struggles for homosexuals and for people of colour in the US are relegated strictly to the past. The historical alliance between drag and trans communities is disavowed. RuPaul's outspoken comments on trans issues as well as the show's continued resistance to trans identification has created a wave of backlash, not least amongst younger trans women and trans feminine people whose perception of drag has now been coloured by the antagonism found on Drag Race (Riedel 2018). It could be argued that since the show does not completely edit out the disruption which occurs when trans contestants have come out on the show that it is at the least engaging with these contemporary issues and struggles. But although the visibility of gender non-conforming contestants has increased (both trans and genderfuck performers have continued to appear on the show) these identifications are always suppressed by the political economy of the show which narrows gender expression to more easily package the queens to a broader (heteronormative) public. $^{4}$

The boundaries of how the competitors perform their drag is linked directly to the ideology of entrepreneurship and the mythology of the American 'go-getter'. Within the inherent socioeconomic context of a free market, it is suggested that any of the contestants can be 4A 2017 demographic suggested that heterosexual women matched the gay male audience for Drag Race one-to-one (see Crawshaw 2017). It should be noted however, that Drag Race is a heavily pirated show and as such its actual viewership demographic is almost impossible to determine with accuracy. 
a potential success; but only under strict conditions. The contestant must be viewed as autonomous and independent while adhering to the characteristics of drag as defined by the show. Thus, in the process of the show each contestant is coached (or rather, disciplined) in terms of 'how to control his conduct, his behaviour, his attitudes, how to intensify his performance, multiply his capacity, how to put himself in his rightful place, where he can be most useful' (Foucault, 2012: 177). The goal of this disciplinary power is to control the contestants in their relations and in their learning, in order to ensure they are docile enough to absorb their potential as a commodity (Foucault, 1979). The multifarious identifications that are now achieving a higher visibility in mainstream culture present a challenge which the discourse of Drag Race aims to contain. Part of the neoliberal fantasy of Drag Race lies in each contestant being able to adapt their body to make themselves saleable. But when we consider the politics of Drag Race, clearly this fantasy is not readily available for all bodies. The limits defined by entrepreneurship ideology rejects those subjects who have already been targeted for exclusion.

\section{Acknowledgements}

This paper would not have been written were it not for the encouragement and guidance of Dr Niall Richardson at the University of Sussex who I thank for his insight and expertise. I would also like to show my gratitude to Emma Fraser for her patience in proof-reading this article and for introducing me to Ru Paul's Drag Race in the first place.

\section{About the Author}

Jonathan Buck is an MA Filmmaking student at the University of Sussex. His work centres around exploring class, identity, and memory.

\section{References}

Aitkenhead, Decca (2018) "RuPaul: 'Drag is a big $f$-you to male-dominated culture"' in The Guardian, 3 March, available at: https://www.theguardian.com/tv-andradio/2018/mar/03/rupaul-drag-race-big-f-you-to-male-dominated-culture

Anthony, Libby (2014) 'Dragging with an accent: Linguistic Stereotypes, Language Barriers and Translingualism' in Daems, Jim (ed), The Makeup of RuPaul's Drag Race: Essays on the Queen of Reality Shows, (North Carolina: Macfarland \& Company), pp 4968 
Brennan, Niall (2017) 'Contradictions Between the Subversive and the Mainstream: Drag Cultures and RuPaul's Drag Race' in Brennan, Niall \& Gudelunas, David (eds) RuPaul's Drag Race and the Shifting Visibility of Drag Culture, (Basingstoke: Palgrave Macmillan), pp 29-43

Buchanan, Kyle (2011) 'RuPaul on Drag Race, Hannah Montana, and 'Those Bitches' Who Stole Annette Bening's Oscar'” April 4, available at: http://www.vulture.com/2011/04/rupaul_on_drag_race_hannah_mon.html

Butler, Judith (1990) Gender Trouble (New York: Routledge)

Butler, Judith, (1992) 'The Body You Want: Liz Kotz interviews Judith Butler' in Artforum: 82-89

Butler, Judith (1993) Bodies That Matter: On the Discursive Limits of 'Sex' (New York: Routledge)

Chow, Broderick (2017) 'Every Little Thing He Does: Entrepreneurship and Appropriation in the Magic Mike Series' in Lateral: Journal of the Cultural Studies Association, Issue 6.1, Spring, available at: http://csalateral.org/issue/6-1/every-little-thing-he-doesentrepreneurship-appropriation-magic-mike-series-chow/\#fnref-1799-3

Cohen, Laurie and Musson, Gill (2000) 'Entrepreneurial Identities: Reflections from Two Case Studies' in Organization 7(1): 31-49

Costa, Alessandra de Sá Mello da and Saraiva, Luiz Alex Silva (2012) 'Hegemonic Discourses on Entrepreneurship as an Ideological Mechanism for the Reproduction of Capitalism', in Organization 19, no. 5

Crawshaw, Tom (2017) 'Almost Half of Drag Race Fans Are Straight Girls According To Research', November 8 available at: https://medium.com/clippings-autumn-2017/almosthalf-of-drag-race-fans-are-straight-girls-according-to-research-616ff76a4c02

Daems, Jim (ed) (2014) The Makeup of RuPaul's Drag Race: Essays on the Queen of Reality Shows, (North Carolina: Macfarland \& Company) pp 3-12

Fiske, John (1990) Television Culture (London: Routledge)

Foucault, Michel (1977) Discipline and Punish: The Birth of the Prison (New York: Random House)

Foucault, Michel (1979). The Microphysics of Power (Graal: São Paulo)

Foucault, Michel (2007) The Order of Discourse (São Paulo: Loyola)

Foucault, Michel (2012). 'The meshes of power', in Michel Foucault, Security, Penalty and Prisons: Dictations (São Paulo: Editora Forense) 
Gill, Rosalind (2007) 'Postfeminist media culture: elements of a sensibility' in European journal of cultural studies, 10 (2). pp. 147-166

Hargraves, Hunter (2011) 'You Better Work: The Commodification of HIV in RuPaul's Drag Race.' In Spectator 31 (2) pp 24-34Harvey, David (2007) A Brief History of Neoliberalism (Oxford: Oxford University Press)

John, Grace (2018) “Exploring The Racial Bias In 'RuPaul's Drag Race”, March 29, available at: https://studybreaks.com/tvfilm/rupauls-drag-race

Kent, Sharmin (2013) 'How 'Drag Race' Gave RuPaul A Comeback - And Made Him A Next-Generation Oprah', Oct 11, available at: https://thinkprogress.org/how-drag-racegave-rupaul-a-comeback-and-made-him-a-next-generation-oprah-21ac812914d8/

Kohlsdorf, Kai (2014) 'Policing the Proper Queer Subject: RuPaul's Drag Race in the Neoliberal 'Post' Moment' in Daems, Jim (ed) The Makeup of RuPaul's Drag Race: Essays on the Queen of Reality Shows, (North Carolina: Macfarland \& Company) 67-87

Kruger, Norris. F. and Brazeal, Deborah. V. (1994) 'Entrepreneurial Potential and Potential Entrepreneurs' in Entrepreneurship Theory and Practice 18(3): 91-104

Marcel, Mary (2014) 'Representing Gender, Race and Realness: The Television World of America's Next Drag Superstars' in Daems, Jim (ed) The Makeup of RuPaul's Drag Race: Essays on the Queen of Reality Shows, (North Carolina: Macfarland \& Company), pp 1330

Marx, Karl (1844) Economic and Philosophical Manuscripts of 1844, Marxists.org, accessed 24 May 2018, https://www.marxists.org/archive/marx/works/1844/manuscripts/needs.htm

Norris, Laurie (2014) 'Of Fish and Feminists: Homonormative Misogyny and the Trans* Queen' in The Makeup of RuPaul's Drag Race: Essays on the Queen of Reality Shows, in Daems, Jim (ed) (North Carolina: Macfarland \& Company) pp 31-48

Molloy, Parker Marie; Reynolds, Daniel; Brydum, Sunnivie (2014). "Carmen Carrera Becomes Lightning Rod in T-Word Debate" in The Advocate, May 28 available at: https://www.advocate.com/politics/transgender/2014/05/28/carmen-carrera-becomeslightning-rod-t-word-debate

Riedel, Samantha (2018) 'A Brief History of How Drag Queens Turned Against the Trans Community' March 10 available at: https://www.them.us/story/how-drag-queens-turnedagainst-the-trans-community

Roberts, Amber (2016) 'Is it time to take the T out of LGBT?' Jan 21 available at: http://www.dazeddigital.com/artsandculture/article/29330/1/is-it-time-to-take-the-t-out-of$\operatorname{lgbt}$ 


\section{for(e)dialogue}

volume 3, Issue 1 (2019): Media and Gender

RuPaul (1995) Lettin' It All Hang Out: An Autobiography, (New York: Hachette Books) Strübel-Scheiner, Jessica (2011) 'Gender Performativity and Self-Perception: Drag as Masquerade' in International Journal of Humanities and Social Science, September, Vol. 1, No.13 pp 12-19

Weber, Breda R. (2008), 'Makeover as Takeover, Scenes of Affective Domination on Makeover TV' in Configurations 15, no.1 